\title{
A 2-month exposure to dietary genistein has sex-dependent effects on serum profile, cardiac protein expression, and aortic morphology in mice
}

\author{
This article was published in the following Dove Press journal: \\ Nutrition and Dietary Supplements \\ 21 March 2014 \\ Number of times this article has been viewed
}

\section{Layla Al-Nakkash \\ Joshua B Martin \\ Jennifer Cannon \\ Ashesh Bhakta \\ Lana Leung \\ Tom L Broderick}

Midwestern University, Arizona College of Osteopathic Medicine, Glendale, AZ, USA
Correspondence: Layla Al-Nakkash Department of Physiology, AZCOM, Midwestern University, 19555 North 59th Avenue, Agave Hall, Room 217-C, Glendale, AZ 85308 USA

Email: lalnak@midwestern.edu
Background: The sex-dependent effects of chronic exposure to dietary genistein on cardiovascular health are poorly understood.

Purpose: This study examined the effects of a genistein-containing diet on cardiovascular plasma markers, aortic morphology, blood pressure, and expression of cardioprotective proteins in male and female mice.

Methods: C57BL/6J mice were fed either genistein diet (600 mg genistein/kg diet; 600G) or a genistein free diet $(0 \mathrm{G})$ for a period of 2 months.

Results: After treatment, male and female mice fed $600 \mathrm{G}$ gained significantly less weight than their control counterparts fed 0G. Plasma insulin levels were significantly decreased in males only, whereas no changes in the other plasma markers were observed with $600 \mathrm{G}$ regardless of sex. Aortae from genistein-fed male mice demonstrated significant decreases in inner and outer luminal diameters and smooth muscle cell density. In female mice fed $600 \mathrm{G}$, no changes in inner and outer luminal diameters were observed compared to female mice fed $0 \mathrm{G}$, but smooth muscle cell density was significantly increased. Despite these differences in aortic morphology, no changes in arterial blood pressure were noted, regardless of sex or diet with genistein. Expression of cardiac glucose transporter type 4 (GLUT4) was increased in male hearts treated with genistein, while expression of endothelium nitric oxide synthase was significantly increased in females fed $600 \mathrm{G}$ compared to controls. However, no differences in inducible nitric oxide synthase protein were observed in all groups studied.

Conclusion: Our data indicate that a 2-month diet with genistein results in changes in aortic morphology and expression of cardiac protein and its effects appear to be sex-dependent.

Keywords: isoflavonic phytoestrogen, diet, plasma markers, cardiac effects

\section{Introduction}

Genistein is a naturally occurring isoflavonic phytoestrogen found in high concentrations in soy products and legumes. ${ }^{1}$ The estrogenic activity of isoflavones has been associated with their structural similarity to steroidal estrogens. ${ }^{2}$ Dietary intake of isoflavones in humans has been associated with a reduced risk of developing osteoporosis and cardiovascular disease, with further claims that increased intake may be beneficial to female reproduction function and reduce the incidence of uterine cancer in postmenopausal women. ${ }^{2}$ Some of the cardioprotective effects of isoflavones have been attributed to an improved lipid and glucose profile, reduction in blood pressure, and improvement in endothelial function and arterial compliance. ${ }^{2}$ While the 
consumption of soy-based food products has been promoted as an alternative treatment to estrogen and is targeted mainly to postmenopausal women, consuming diets rich in soy may also be of benefit to the male population because of the increased incidence of cardiovascular disease reported in men compared to aged-matched premenopausal women. ${ }^{3-5}$

While benefits of soy-based consumption on blood pressure and other parameters of cardiovascular health have been relatively widely described, ${ }^{6-8}$ the long-term effects of genistein in relevant experimental models remain relatively unclear. We have shown that administering genistein for a period of 2 days by subcutaneous injection at the concentration of $250 \mathrm{mg} / \mathrm{kg}$ body weight in the ovariectomized (OVX) rat causes a dose-dependent increase in cardiac output in isolated working hearts and increased ischemic tolerance to reperfusion injury. ${ }^{9}$ Extending this treatment for a period of 2 weeks induces estrogen-like effects in the OVX rat, including decreased body weight, bradycardia, and a reduction in aortic pulse pressure. ${ }^{10}$ Alternatively, we have recently shown that feeding mice with intact ovarian function a genisteincontaining diet (600 $\mathrm{mg}$ genistein $/ \mathrm{kg}$ diet) for a period of 1 month produces favorable effects on glucose metabolism, cardiovascular risk factors, and aortic reactivity. ${ }^{11}$ Taken together, the outcome of studies examining the role of genistein is dependent on several factors, including differences in the experimental models used, age and sex of animals, duration of treatment, and route of administration of genistein.

Direct comparisons of the effects of dietary genistein consumption in both males and females are less rigorously described. Further, much less is known regarding the effects of chronic genistein consumption on indices of cardiovascular function and health. This deserves to be explored based on the clinical studies showing that the prevalence of hypertension is greater in males compared with females before the onset of menopause. We have previously described, nonetheless, the changes in vascular function in the mouse following 1 month dietary genistein consumption. ${ }^{11}$ Mice fed a genisteincontaining diet for 1 month exhibit significant differences in vascular aortic reactivity. Indeed, both male and female mice fed a diet containing $600 \mathrm{mg}$ genistein $/ \mathrm{kg}$ generate increased tension compared to mice fed a diet devoid of this phytoestrogen. ${ }^{11}$

Therefore, the purpose of the present study was to examine the effects of a longer duration of dietary genistein treatment ( 2 months) on common plasma markers of cardiovascular health and indices of in vivo vascular function in both male and female mice. These data are an extension of our previous administration of genistein, and are aimed to determine the chronic effects of genistein on key markers of cardiovascular health.

\section{Materials and methods Animals and treatment protocol with genistein}

C57BL/6J female and male mice were purchased from Jackson Laboratory (Bar Harbor, ME, USA) at 4-6 weeks of age. Mice were acclimated at the institution housing facility for a period of 1 week, followed by a further transition period of 3 days from standard rodent chow to the specialized genistein-containing or genistein-free diets. Experimental mice were fed a diet containing $600 \mathrm{mg}$ genistein $/ \mathrm{kg}$ (600G) for a period of 2 months, whereas control mice were fed a diet free of genistein $(0 \mathrm{G})$, as previously reported. ${ }^{12}$ Diets were casein based and specially formulated as per our previous studies, ${ }^{11,12}$ and purchased from Dyets Inc., (Bethlehem, PA, USA). Diet composition is described in Table 1. Animals were housed two per cage, with a 12:12 hour light-dark cycle, and given either the genistein-based or genistein-free diet and water ad libitum. Body weight was measured weekly during the study, and general health monitored biweekly. Following the 2-month diet, mice were asphyxiated in an atmosphere of $100 \% \mathrm{CO}_{2}$, followed by surgical thoracotomy to induce pneumothorax. Blood was immediately obtained by cardiac puncture and centrifuged for the collection of plasma. The aortae were dissected and frozen in either Tissue-Tek OCT compound (Sakura Finetek, Torrance, CA, USA) for morphology or in liquid nitrogen for the determination of adenosine $3^{\prime}, 5^{\prime}$-cyclic monophosphate (cAMP) and cyclic guanosine monophosphate (cGMP) content. Hearts were removed and wet weight was immediately obtained prior to

Table I Composition of experimental diets

\begin{tabular}{lll}
\hline Ingredient & OG & 600G \\
\hline Casein & 200 & 200 \\
Corn starch & 396.9 & 396.9 \\
Dyetrose & 132 & 132 \\
Sucrose & 100 & 100 \\
Cellulose & 50 & 50 \\
Safflower oil/tBHQ & $20 / 0.004$ & $20 / 0.004$ \\
Corn oil & 50 & 50 \\
Mineral mix \#210025 & 35 & 35 \\
Vitamin mix \#310025 & 10 & 10 \\
Choline bitartrate & 2.5 & 2.5 \\
DL-methionine & 3.0 & 3.0 \\
Genistein & 0 & 0.6 \\
\hline
\end{tabular}

Note: aLC Laboratories (Woborn, MA, USA).

Abbreviations: 0G, genistein-free diet; 600G, $600 \mathrm{mg}$ genistein $/ \mathrm{kg}$ diet; tBHQ, tertiary butylhydroquinone. 
being snap frozen in liquid nitrogen and stored at $-80^{\circ} \mathrm{C}$ until use. From each animal, the liver was removed and wet weight obtained. Ratios of heart-to-body weight and liver-to-body weight were calculated by simple division. Animals used in this study were cared for in accordance with the recommendations in the Guide for the Care and Use of Laboratory Animals. ${ }^{13}$ This study was approved by the Midwestern University Institutional Animal Care and Use Committee.

\section{Blood pressure measurements}

Measurement of heart rate and systolic, diastolic, and mean arterial pressure were obtained in mice using a pneumatic tail cuff device (NIBP; Columbus Instruments, Columbus, $\mathrm{OH}$, USA). Mice were acclimated to both being in the restrainer and tail heating at least three times (over several days) prior to taking the final blood pressure measurements. From these measurements, pulse pressure (systolic blood pressure diastolic blood pressure), and cardiac work ([pulse pressure $x$ heart rate] $/ 1,000$ ) were calculated. Readings of pressure were obtained at the end of the study and an average of five to seven recordings was obtained per mouse and reported.

\section{Measurement of plasma biomarkers}

Cardiovascular markers were measured from mouse plasma using commercially available assay kits. Kits for nonesterified fatty acid (NEFA-HR2) and glucose were purchased from Wako Diagnostics (Richmond, VA, USA). The insulin enzyme-linked immunosorbent assay (ELISA) kit was obtained from EMD Millipore Corporation (Billerica, MA, USA), and cholesterol from Cayman Chemical Company (Ann Arbor, MI, USA). Manufacturer specifications were followed for each assay.

\section{Aortic morphology}

Frozen sliced sections $(8 \mu \mathrm{m})$ of aorta were stained with a standard hematoxylin and eosin protocol prior to performing the morphometric analyses to evaluate wall thickness, as previously reported. ${ }^{11}$ Images of the aortic sections were taken at $20 \times$ magnification with an Olympus Vanox (AHBS3; Olympus, Center Valley, PA, USA) light microscope. Measures from the stained aortic ring sections were taken using ImageJ (National Institutes of Health [NIH], Bethesda, MD, USA) and used for the determination of inner luminal area and outer serosal area. From these area measurements, the inner luminal diameter and outer serosal diameters were calculated using the following formula:

$$
\text { Area }=\Pi \times \text { radius }^{2} .
$$

Wall thickness was then determined using the difference between the inner luminal area and outer serosal area diameters. Between six and ten separate sections of aorta per mouse were used for morphologic measurements, with the average presented. In addition, cell nuclei counts in a given area of each section of aorta ( $400 \times 100$ pixels) were obtained, and averages of three to six measures/mouse were themselves averaged. Cell nuclei count/given area was utilized as a correlate of cell density.

\section{Immunoassay of cAMP/cGMP}

Frozen aortic tissue was weighed and homogenized in ten volumes of $5 \%$ trichloroacetic acid in a glass-Teflon tissue grinder. Samples were centrifuged at 5,000 rpm for 10 minutes. Supernatants were extracted with three volumes of water-saturated ether. Aqueous extracts were dried and reconstituted with assay buffer ED2. Commercially available kits were used for the determination of tissue levels of cAMP and cGMP (R\&D Systems Inc., Minneapolis, MN, USA).

\section{Measurement of cardiac glucose transporter type 4 (GLUT4), inducible nitric oxide synthase (iNOS), and endothelial nitric oxide synthase (eNOS) protein expression}

Standard Western blot techniques were utilized to detect GLUT4 ( 40-48 kD), iNOS ( 130 kD), and eNOS ( 130 kD) protein. Total protein concentration of whole heart tissues was determined (Thermo Fisher Scientific Inc., Rockford, IL, USA). In brief, $25 \mu \mathrm{L}$ of sample was loaded on $10 \%$ Bis-Tris gels (GLUT4) or 10\% Tris-glycine gels (iNOS and eNOS) and run at $200 \mathrm{~V}$ (GLUT4) or $100 \mathrm{~V}$ (iNOS and eNOS) for $\sim 50$ minutes. Gels were transferred at $100 \mathrm{~V}$ for 40 minutes (GLUT4) or $30 \mathrm{~V}$ for 2 hours (iNOS and eNOS), at $4^{\circ} \mathrm{C}$. Blots were incubated with primary antibody (1:5,000 anti-GLUT4 from rabbit, EMD Millipore Corporation; 1:500 anti-iNOS or anti-eNOS, Santa Cruz Biotechnology Inc., Santa Cruz, CA, USA) overnight at $4{ }^{\circ} \mathrm{C}$ in $5 \%$ milk in phosphate buffered saline solution $+0.1 \%$ Tween (PBST). Blots were then incubated with secondary antibody $(1: 1,200$ antirabbit immunoglobulin G [IgG]; GE Healthcare Bio-Sciences, Pittsburgh, PA, USA) in 3\% milk in PBST for 1 hour at room temperature. Proteins were visualized with enhanced chemiluminescent substrate (GE Healthcare Bio-Sciences).

\section{Statistics}

Statistical analysis was performed using Graphpad Prism 4 (Graphpad Software Inc., La Jolla, CA, USA). All values are 
reported as the mean \pm standard error of the mean (SEM). A one-way analysis of variance (ANOVA), followed by the Newman-Keuls test, was used to determine differences between all four diet groups. Significance is shown as $P<0.05$.

\section{Results}

\section{Physical characteristics of mice}

The effect of the 2-month genistein diet on physical characteristics of male and female mice is presented in Table 2. At the beginning of the treatment study, there were no significant differences in body weight between any of the four groups. Body weight measured after the 2-month study period was significantly higher (by $\sim 6 \mathrm{~g}$ ) in male control mice compared to female control mice. Both female and male mice fed genistein diet weighed significantly less than their respective control counterparts (both by $\sim 3 \mathrm{~g}$ ). Furthermore, heart-tobody weight ratio and liver weight were significantly higher in 0G males compared to female counterparts, likely due to the increased final body weight in control male mice compared to control female mice.

\section{Cardiovascular functional measures}

Table 3 shows the thoracic aortae wall measurements obtained from mice after treatment with the genistein-containing diet. Inner luminal diameter and outer diameter were significantly lower with genistein-treated males compared to control males, albeit without change in wall thickness. There were no changes in these parameters in aortae from female mice. The wall-to-lumen ratio of male or female mice fed genistein was not different to their respective controls. However, control female mice had a significantly increased wall-to-lumen ratio compared to control male mice. Quantification of smooth muscle density indicated a significant decrease in male mice fed genistein, whereas in female mice fed genistein, a significant increase was observed. A significant decrease in smooth muscle density (nuclei) was seen between control female mice and control male mice. Despite the differences in smooth muscle density (nuclei), there were no associated changes in total aortic cAMP or cGMP content.

In vivo measures of cardiovascular function obtained following the diet treatment are shown in Table 4. There were no differences between male and female mice or in genistein-treated mice in systolic blood pressure, diastolic blood pressure, mean arterial pressure, pulse pressure, cardiac work, and heart rate.

\section{Cardiovascular plasma markers}

The effects of genistein on common plasma markers of cardiovascular health are presented in Figure 1. Plasma insulin levels were lowered by genistein diet in male mice, and male control mice had significantly higher insulin levels than female counterparts (Figure 1A). Plasma glucose levels were significantly higher in control male mice compared to control female mice (Figure 1B). Calculating the insulin-to-glucose ratio from these treatment groups demonstrates that control male mice had higher ratios than control female mice (Figure 1C). Plasma NEFA and cholesterol levels were higher in control male mice compared to control females (Figure 1D and E). Treatment with genistein had no effect on either plasma NEFA or cholesterol levels regardless of the sex of mice.

\section{Protein expression of cardiac GLUT4 and nitric oxide synthase}

Figure 2 illustrates the effect of a 2-month genistein diet on expression of whole cardiac GLUT4, iNOS, and eNOS protein. Expression of GLUT4 in heart was significantly increased in male mice fed $600 \mathrm{G}$ compared to males fed a $0 \mathrm{G}$ diet (Figure 2A and B). In hearts from female mice, however, no effect of genistein was observed (Figure 2A and B). Although iNOS expression was not different between treatment groups, differences in eNOS expression were seen. Indeed, a significant increase in eNOS expression was seen in genistein-fed female mice, whereas no change was noted in male mice (Figure $2 \mathrm{~A}$ and $\mathrm{B})$.

Table 2 The effects of a 2-month genistein diet treatment period on physical characteristics of male and female mice

\begin{tabular}{|c|c|c|c|c|}
\hline \multirow[t]{2}{*}{ Physical characteristic } & \multicolumn{2}{|l|}{ Males } & \multicolumn{2}{|l|}{ Females } \\
\hline & OG & $600 \mathrm{G}$ & OG & $600 \mathrm{G}$ \\
\hline Start body weight (g) & $18.40 \pm 0.64$ & $18.24 \pm 0.69$ & $17.31 \pm 0.65$ & $|7.33 \pm 0.6|$ \\
\hline End body weight (g) & $28.86 \pm 0.64 *$ & $26.13 \pm 0.50^{\dagger}$ & $22.82 \pm 0.78$ & $19.91 \pm 0.36^{\dagger}$ \\
\hline Heart weight (g) & $0.142 \pm 0.004$ & $0.125 \pm 0.004$ & $0.127 \pm 0.008$ & $0.117 \pm 0.005$ \\
\hline Heart-to-body weight ratio & $0.0048 \pm 0.0002 *$ & $0.0048 \pm 0.000 \mathrm{I}$ & $0.0058 \pm 0.0003$ & $0.0060 \pm 0.0002$ \\
\hline Liver weight $(\mathrm{g})$ & $1.17 \pm 0.05^{*}$ & $1.15 \pm 0.04$ & $0.84 \pm 0.03$ & $0.86 \pm 0.04$ \\
\hline Liver-to-body weight ratio & $0.0405 \pm 0.0013$ & $0.0446 \pm 0.0007$ & $0.0384 \pm 0.001 \mathrm{I}$ & $0.0444 \pm 0.0018^{\dagger}$ \\
\hline
\end{tabular}

Notes: Values are reported as mean \pm standard error of the mean. $n=10-16 /$ group. $*$ Denotes $P<0.05$ compared to female $0 G$; ${ }^{\dagger}$ denotes $P<0.05$, genistein-dependent effect within the same sex.

Abbreviations: 0G, genistein-free diet; 600G, 600 mg genistein/kg diet; g, grams. 
Table 3 The effects of a 2-month genistein diet treatment period on thoracic aortae measures of male and female mice

\begin{tabular}{|c|c|c|c|c|}
\hline \multirow[t]{2}{*}{ Aortic measure } & \multicolumn{2}{|l|}{ Males } & \multicolumn{2}{|l|}{ Females } \\
\hline & OG & $600 \mathrm{G}$ & $\mathbf{O G}$ & $600 \mathrm{G}$ \\
\hline Inner diameter $(\mu \mathrm{m})$ & $324.2 \pm 8.5$ & $293.2 \pm 11.0^{\dagger}$ & $299.1 \pm 5.9$ & $289.2 \pm 5.9$ \\
\hline Outer diameter $(\mu \mathrm{m})$ & $361.1 \pm 7.6$ & $333.3 \pm 11.2^{\dagger}$ & $343.9 \pm 6.7$ & $326.0 \pm 4.3$ \\
\hline Wall thickness $(\mu \mathrm{m})$ & $36.8 \pm 2.2^{*}$ & $40.0 \pm 0.9$ & $44.9 \pm 1.9$ & $36.8 \pm 3.4$ \\
\hline Wall-to-lumen ratio & $0.114 \pm 0.009 *$ & $0.137 \pm 0.006$ & $0.150 \pm 0.007$ & $0.128 \pm 0.014$ \\
\hline $\begin{array}{l}\text { Smooth muscle cell density } \\
\text { (cells/40,000 pixel area) }\end{array}$ & $55.6 \pm 4.4^{*}$ & $39.1 \pm 4.2^{\dagger}$ & $42.2 \pm 6.2$ & $65.9 \pm 3.1^{\dagger}$ \\
\hline Total cAMP (pmol/mL) & $3.0 \pm 0.8$ & $4.8 \pm 0.9$ & $2.9 \pm 0.3$ & $4.8 \pm 0.9$ \\
\hline Total cGMP (pmol/mL) & $5.4 \pm 0.5$ & $4.9 \pm 0.8$ & $8.4 \pm 0.7$ & $6.2 \pm 0.9$ \\
\hline
\end{tabular}

Notes: Values are reported as mean \pm standard error of the mean. $n=6-10 /$ group. *Denotes $P<0.05$ compared to female $0 \mathrm{G}$; ${ }^{\dagger}$ denotes $P<0.05$, genistein-dependent effect within the same sex.

Abbreviations: 0G, genistein-free diet; 600G, 600 mg genistein/kg diet; cAMP, cyclic adenosine monophosphate; cGMP, cyclic guanosine monophosphate.

\section{Discussion}

The ability of the naturally occurring phytoestrogen genistein to bind to estrogen receptors and exert estrogen-like effects has deterred the proposed use of genistein as a natural alternative to estrogen replacement. ${ }^{14}$ Consumption of a diet containing a high concentration of phytoestrogen such as genistein has been associated with a decreased risk of cardiovascular disease, without increasing the risk of developing certain cancers of the reproductive tract. ${ }^{15,16}$ We selected a diet containing $600 \mathrm{G}$ and predicted that genistein would have advantageous effects on several markers of cardiovascular health. With this concentration of genistein in the diet, we routinely obtain plasma genistein levels of $7.7 \pm 4.0 \mu \mathrm{mol} / \mathrm{L}$ and $4.2 \pm 2.3 \mu \mathrm{mol} / \mathrm{L}$ in intact female and male mice, respectively, ${ }^{12}$ indicating that continuous consumption of genistein can result in sustained plasma levels in the low $\mu \mathrm{mol} / \mathrm{L}$ ranges. The plasma levels of genistein we have previously measured with this amount of genistein in the diet (600G) are comparable to studies by other investigators that have also correlated genistein intake with concomitant changes in plasma genistein concentration. ${ }^{17-19}$ More importantly, these levels are comparable to those measured following consump- tion of a soy milk diet in humans, which has been shown to result in similar plasma genistein concentrations. ${ }^{17,20}$

Genistein has been previously shown to reduce fat weight and fasting blood glucose and improve lipid levels. ${ }^{21-24} \mathrm{We}$ also noted a significant decrease in body weight in the 600Gfed females and males compared to their $0 \mathrm{G}$ counterparts ( $\sim 13 \%$ and $10 \%$, respectively). Given the documented association of genistein with augmented lipolysis or apoptosis of adipocytes, ${ }^{24}$ we postulate that genistein exerts similar effects in this study in both male and female mice. These data are in contrast to our previous findings after 1 month of $600 \mathrm{G}$, whereby only males demonstrated a significant decrease in body weight. ${ }^{11}$ Thus, it appears that genistein's ability to induce weight loss is duration-dependent, requiring an extended treatment period in females, but with the same outcome.

Our current evidence supports that genistein, administered for 2 months via diet, had no effect on blood pressure in either male or female mice. This is consistent with our previous studies demonstrating that after a 1 -month $600 \mathrm{G}$ diet, there were no genistein-mediated changes in blood pressure in male or female mice. Despite the fact that we did not observe changes

Table 4 The effects of a 2-month genistein diet treatment period on blood pressure, heart rate, pulse pressure, and cardiac work of male and female mice

\begin{tabular}{|c|c|c|c|c|}
\hline \multirow[t]{2}{*}{ Index of arterial pressure } & \multicolumn{2}{|l|}{ Males } & \multicolumn{2}{|l|}{ Females } \\
\hline & $\mathbf{O G}$ & $600 \mathrm{G}$ & $\mathbf{0 G}$ & $600 \mathrm{G}$ \\
\hline $\mathrm{SBP}(\mathrm{mmHg})$ & $105.1 \pm 3.4$ & $98.3 \pm 2.6$ & $107.0 \pm 2.6$ & $109.4 \pm 5.1$ \\
\hline $\mathrm{DBP}(\mathrm{mmHg})$ & $79.8 \pm 2.9$ & $74.7 \pm 2.4$ & $80.7 \pm 2.5$ & $82.9 \pm 4.6$ \\
\hline MAP $(\mathrm{mmHg})$ & $88.2 \pm 2.9$ & $82.6 \pm 2.4$ & $89.5 \pm 2.5$ & $91.7 \pm 4.7$ \\
\hline Pulse pressure $(\mathrm{mmHg})$ & $25.3 \pm 1.3$ & $23.6 \pm 1.3$ & $26.3 \pm 1.1$ & $26.5 \pm 0.9$ \\
\hline Cardiac work (mmHg*beats/min) & $17.5 \pm 0.8$ & $16.6 \pm 1.1$ & $17.9 \pm 0.6$ & $18.7 \pm 0.7$ \\
\hline Heart rate (beats/min) & $693.6 \pm 12.5$ & $700.6 \pm 10.1$ & $682.2 \pm 19.4$ & $724.9 \pm I I .7$ \\
\hline
\end{tabular}

Notes: Values are reported as mean \pm standard error of the mean. $n=8-15$ /group.

Abbreviations: 0G, genistein-free diet; 600G, 600 mg genistein/kg diet; DBP, diastolic blood pressure; MAP, mean arterial blood pressure; min, minute; SBP, systolic blood pressure. 


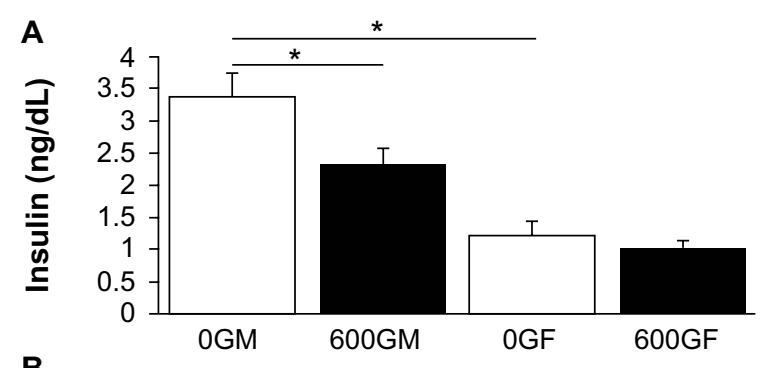

B
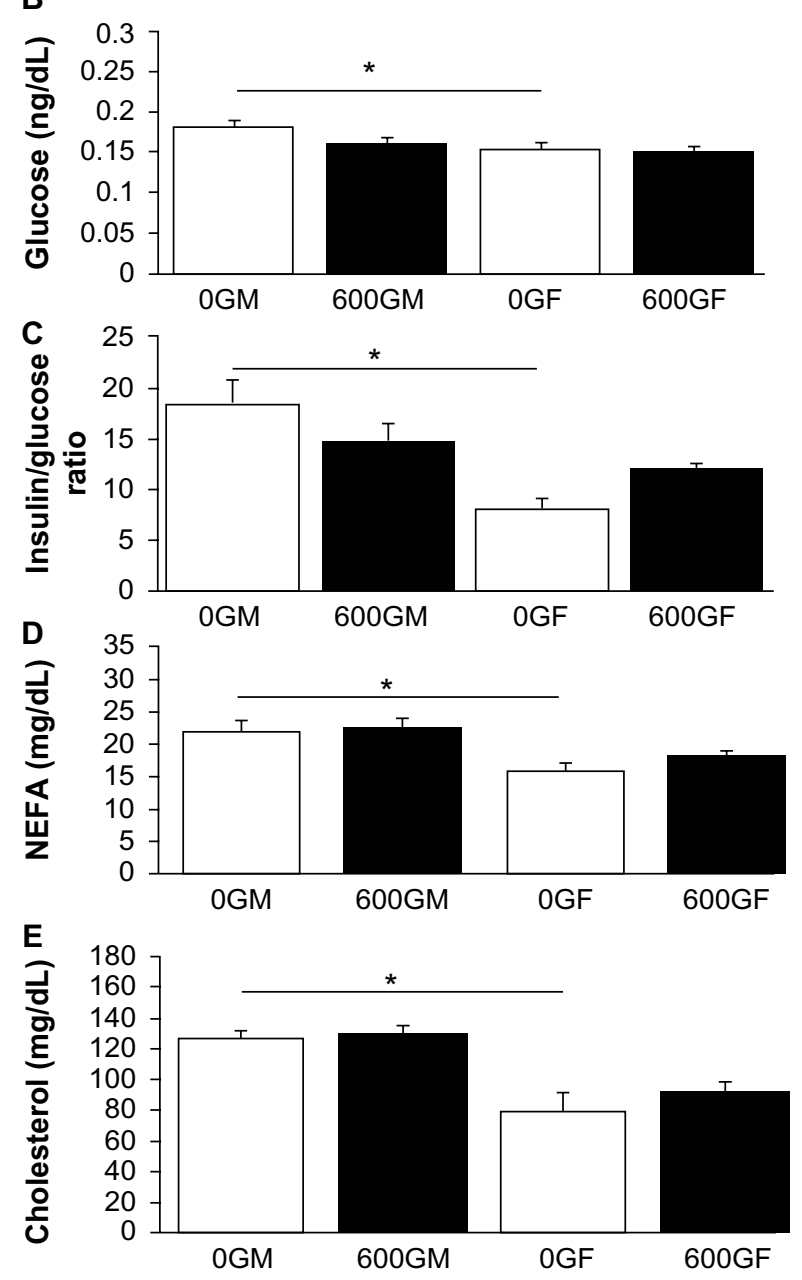

Figure I Effect of genistein treatment on plasma insulin (A), glucose (B), insulin/ glucose ratio $(\mathbf{C})$, nonesterified free fatty acids (D), and cholesterol (E).

Notes: The genistein-free fed groups (OG) are represented by open bars, and the genistein-fed groups (600G) are represented by the solid bars. Values are reported as mean \pm standard error of the mean for nine to ten mice in each group. *Denotes $P<0.05$.

Abbreviations: OGF, genistein-free fed females; 0GM, genistein-free fed males; 600GF, $600 \mathrm{mg}$ genistein/kg diet-fed females; 600GM, $600 \mathrm{mg}$ genistein $/ \mathrm{kg}$ diet-fed males; NEFA, nonesterified fatty acid.

in blood pressure with $600 \mathrm{G}$ diet after 2 months, we aimed to determine potential changes in thoracic aortic morphology. Aortic wall thickness was unchanged in males and females fed $600 \mathrm{G}$ compared to their $0 \mathrm{G}$ controls. Female controls (0G) had a significantly wider wall thickness compared to male controls; however, there was a trend for a sex-dependent
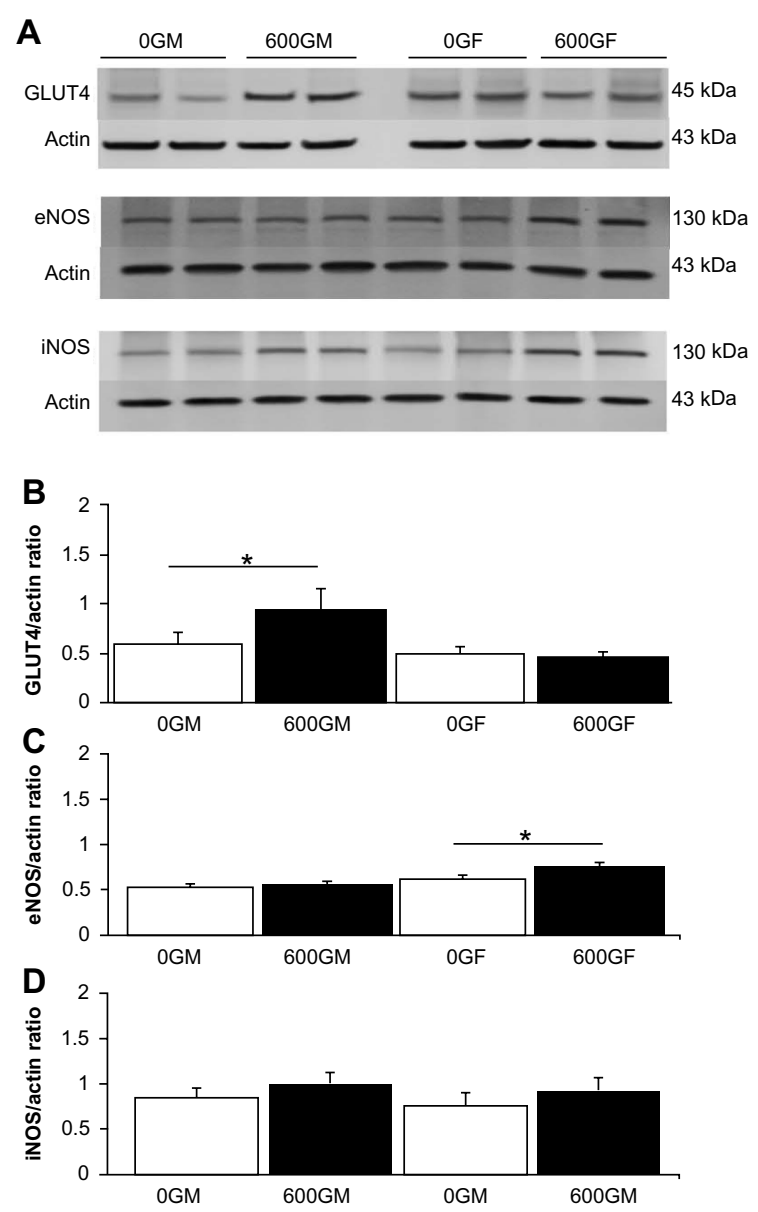

Figure 2 Effect of genistein treatment on total GLUT4, eNOS, and iNOS protein expression in male and female cardiac tissue.

Notes: (A) Typical Western blot demonstrating GLUT4, eNOS, iNOS, and actin expression in cardiac tissue from two samples each of 600G- and 0G-treated male and female mice. GLUT4, eNOS, iNOS, and actin bands were observed at 40-43 kDa, $130 \mathrm{kDa}, 130 \mathrm{kDa}$, and $43 \mathrm{kDa}$, respectively. (B) Average GLUT4/actin ratio comparing 600G- (solid bars) and 0G- (open bars) treated male and female mice ( $n=10 /$ group). (C) Average eNOS/actin ratio comparing 600G- (solid bars) and OG- (open bars) treated male and female mice ( $n=10 /$ group). (D) Average iNOS/ actin ratio comparing 600G- (solid bars) and 0G- (open bars) treated male and female mice ( $n=10 /$ group). Values are reported as mean \pm standard error of the mean, *Denotes $P<0.05$.

Abbreviations: 0GF, genistein-free fed females; 0GM, genistein-free fed males; 600GF, $600 \mathrm{mg}$ genistein/kg diet-fed females; 600GM, $600 \mathrm{mg}$ genistein/kg diet-fed males; GLUT4, glucose transporter type 4; eNOS, endothelial nitric oxide synthase; iNOS, inducible nitric oxide synthase.

increase in wall thickness in females compared to males, and a trend for a genistein-dependent decrease in females. We correlated nuclei count in a given area measured to be directly associated to cell density. Measurements of smooth muscle cell density within a consistent area of aorta indicated that genistein significantly increased smooth muscle cell number in females (actually bringing it closer to the male control values) and significantly decreased smooth muscle cell number in males (perhaps indicating a genistein-dependent decrease in cell number in males); moreover, there was a significant sexdependent decrease in $0 \mathrm{G}$ females compared to $0 \mathrm{G}$ males. 
Evidence suggests that in male rats, genistein decreased pulmonary artery smooth muscle cell proliferation, ${ }^{25}$ which is consistent with our measured decrease in nuclei count in males only. Consistent with such evidence, genistein has been shown to be involved in shape-activated changes in cellular morphology in vascular smooth muscle cells, effects that are mediated via changes in ERK1/2 activity. ${ }^{26}$ Interestingly, genistein has also been shown to decrease hepatic stellate cell proliferation in a dose-dependent manner. ${ }^{27}$ Further determination of the cellular signaling pathways and transcription factors involved is required to assess how genistein exerts its sex-dependent effects on murine aortic vascular structure. In addition, there were no changes in total aortic cGMP or cAMP levels in female and male mice. It is possible that an increased dose of genistein in the diet and/or increased duration of exposure may exert different effects; future studies should examine whether genistein induces changes in blood pressure and similar changes in the vascular wall in both sexes after consumption of more than $600 \mathrm{mg}$ genistein $/ \mathrm{kg}$ diet for longer than 2 months.

The effects of genistein on glucose uptake in tissues and insulin sensitivity have been relatively well established. An increase in insulin sensitivity was reported in postmenopausal women treated with $54 \mathrm{mg}$ genistein/day for a period of 24 weeks, ${ }^{28}$ and in male Wistar rats receiving $1 \mathrm{mg}$ genistein/kg body weight for 44 days, ${ }^{29}$ which is consistent with our findings in male mice after 1 month of $600 \mathrm{G} .{ }^{11}$ Interestingly, we found that administration of a genisteincontaining diet for 2 months resulted in a significant decrease in plasma insulin in male mice (but not in females). This is in contrast to our previous data whereby genistein administration for 1 month increased plasma insulin in males, ${ }^{11}$ Several mechanisms have been postulated to explain genistein's stimulatory action on insulin secretion, including inhibition of tyrosine kinase activity ${ }^{30}$ and activation of the cAMP/PKA ERK1/2 and PLC/PKC pathways. ${ }^{31,32}$ Explaining the increase in insulin sensitivity in tissues is, as expected, primarily due to an increase in expression and translocation of the glucose transporter GLUT4. In skeletal muscle and L6 myotubes, several reports consistently show that genistein increases glucose uptake via up-regulation of both GLUT4 and insulinindependent mechanisms. ${ }^{33-35}$ Unlike skeletal muscle, the effects of genistein treatment on GLUT4 expression in heart tissue are variable, and appear to display changes that are both time and model dependent. An acute 2-day treatment in OVX rats decreases cardiac GLUT4 expression, despite hearts exhibiting increased ischemic tolerance. ${ }^{9}$ A treatment period with genistein for 2 weeks in OVX rats produces favorable estrogen-like effects on blood markers and blood pressure, but no effect on GLUT4 expression in hearts. However, in the present study following 2 months of treatment, we observed a significant increase in the levels of cardiac GLUT4 in male hearts, but interestingly no effect was seen in female hearts. The reasons for these discrepancies in GLUT4 expression in response to genistein are unknown, but may relate to differences in the rodent model used, duration of treatment, and presence or absence of ovarian function in rodents. Whether the genistein-mediated decrease in plasma insulin levels in males is associated with a concomitant increase in GLUT4 expression in skeletal muscle (coinciding with our noted increase in cardiac GLUT4 expression), remains to be seen. Nevertheless, our data suggest that at least in males, genistein improves insulin sensitivity. Understanding whether genistein diet can improve insulin sensitivity, at least in males, via effects on glucose uptake in skeletal muscle and/or can modify pancreatic function, requires further investigation which is outside the scope of the current study. That said, Fu et al have previously demonstrated that dietary intake of genistein in diabetic mice significantly improved hyperglycemia and blood insulin levels, thus implicating the potential benefits of genistein in diabetes. ${ }^{32}$

Nitric oxide is synthesized from L-arginine by nitric oxide synthases, including eNOS, located primarily in endocardial and endothelial cells, and in cardiomyocytes. ${ }^{36}$ Expression of eNOS in the heart is important in regulating vasodilation and coronary flow, as well as facets of heart function and cell growth. In the present study, cardiac eNOS expression was increased in female mice treated with genistein, suggesting that beneficial changes within the heart have occurred. Based on the indirect parameters of heart function determined from arterial blood pressure, mechanical function was not altered in female hearts treated with genistein. Although this approach of assessing heart function from arterial pressure is clearly a limitation, we have previously reported that genistein induces a significant inotropic response and increases cardiac output in isolated working hearts from OVX rats. ${ }^{9}$ These effects are consistent with eNOS-mediated changes on force-frequency relationship and cardiac muscle stretch with genistein, ${ }^{36-38}$ and eNOS-mediated protective effects of genistein on isoproterenol-induced cardiac hypertrophy in rats. ${ }^{39}$

These studies demonstrate effects of genistein on several markers of cardiovascular health. While epidemiological studies advertise the benefits of soy-based foods in human diet, the long-term effects of consumption of such compounds remains unclear. ${ }^{40}$ Given the pluripotent actions of genistein on tissues, it is not surprising there should be sex-dependent 
effects and effects that vary depending upon the presence or absence of endogenous estrogen (ie, in menopausal or ovariectomized animal models). Indeed, genistein has a similar potency to $17 \beta$-estradiol and can activate estrogen receptors and estrogen-dependent pathways. ${ }^{41}$

\section{Conclusion}

The results of this study demonstrate incongruent effects of genistein and sex on cardiovascular parameters in both intact male and female mice. Genistein-mediated effects on insulin levels were sex dependent (noted in males, not females). Genistein-mediated effects on cardiac eNOS levels were sex dependent (noted in females, not males). Genisteindependent changes in aortic nuclei counts were noted in both males and females. Our findings demonstrate varying effects with genistein that are both duration dependent and sex dependent; thus, the long-term dietary effects of this phytoestrogen on cardiovascular health should be noted with some degree of prudence. Given that genistein supplements are readily available, it is important to have an understanding of the effects of chronic use of this compound, on parameters of the cardiovascular system. These studies have implications for cardiovascular disease prevention in men and in pre- and postmenopausal women.

\section{Acknowledgments}

The authors thank the Office of Research and Sponsored Program, Midwestern University (TLB, LAN), and The Soy Health Research Program (LAN) for financial support for this project.

\section{Disclosure}

The authors report no conflicts of interest in this work.

\section{References}

1. Vincent A, Ruan M, Fitzpatrick LA. Gender differences in the effect of genistein on vascular smooth muscle cells: a possible cardioprotective effect? J Gend Specif Med. 2001;4(1):28-34.

2. Chin-Dusting JP, Fisher LJ, Lewis TV, Piekarska A, Nestel PJ, Husband A. The vascular activity of some isoflavone metabolites: implications for a cardioprotective role. Br J Pharmacol. 2001;133(4):595-605.

3. Palatini P, Mos L, Santonastaso M, et al. Premenopausal women have increased risk of hypertensive target organ damage compared with men of similar age. J Womens Health (Larchmt). 2011;20(8):1175-1181.

4. Leuzzi C, Marzullo R, Modena MG. [Is menopause a risk factor for ischemic heart disease in women?]. G Ital Cardiol (Rome). 2012;13(6): 401-406. Italian.

5. Maranon R, Reckelhoff JF. Sex and gender differences in control of blood pressure. Clin Sci (Lond). 2013;125(7):311-318.

6. Teede HJ, Dalais FS, Kotsopoulos D, Liang YL, Davis S, McGrath BP. Dietary soy has both beneficial and potentially adverse cardiovascular effects: a placebo-controlled study in men and postmenopausal women. J Clin Endocrinol Metab. 2001;86(7):3053-3060.
7. Mahn K, Borrás C, Knock GA, et al. Dietary soy isoflavone induced increases in antioxidant and eNOS gene expression lead to improved endothelial function and reduced blood pressure in vivo. FASEB $J$. 2005;19(12):1755-1757.

8. Teede HJ, Giannopoulos D, Dalais FS, Hodgson J, McGrath BP. Randomised, controlled, cross-over trial of soy protein with isoflavones on blood pressure and arterial function in hypertensive subjects. $J \mathrm{Am}$ Coll Nutr. 2006;25(6):533-540.

9. Al-Nakkash L, Markus B, Bowden K, Batia LM, Prozialeck WC, Broderick TL. Effects of acute and 2-day genistein treatment on cardiac function and ischemic tolerance in ovariectomized rats. Gend Med. 2009;6(3):488-497.

10. Al-Nakkash L, Markus B, Batia L, Prozialeck WC, Broderick TL. Genistein induces estrogen-like effects in ovariectomized rats but fails to increase cardiac GLUT4 and oxidative stress. J Med Food. 2010;13(6): 1369-1375.

11. Al-Nakkash L, Martin JB, Petty D, et al. Dietary genistein induces sexdependent effects on murine body weight, serum profiles, and vascular function of thoracic aortae. Gend Med. 2012;9(5):295-308.

12. Al-Nakkash L, Clarke LL, Rottinghaus GE, Chen YJ, Cooper K, Rubin LJ. Dietary genistein stimulates anion secretion across female murine intestine. J Nutr. 2006;136(11):2785-2790.

13. The National Academies Press. Guide for the care and use of laboratory animals. 8th ed. Washington, DC: The National Academies Press; 2007. Available from: http://grants.nih.gov/grants/olaw/Guide-for-the-careand-use-of-laboratory-animals.pdf. Accessed February 25, 2014.

14. Suetsugi M, Su L, Karlsberg K, Yuan YC, Chen S. Flavone and isoflavone phytoestrogens are agonists of estrogen-related receptors. Mol Cancer Res. 2003;1(13):981-991.

15. Miyake A, Takeda T, Isobe A, et al. Repressive effect of the phytoestrogen genistein on estradiol-induced uterine leiomyoma cell proliferation. Gynecol Endocrinol. 2009;25(6):403-409.

16. Bandera EV, King M, Chandran U, Paddock LE, Rodriguez-Rodriguez L, Olson SH. Phytoestrogen consumption from foods and supplements and epithelial ovarian cancer risk: a population-based case control study. BMC Womens Health. 2011;11:40.

17. Hendrich S, Lee KW, Xu X, Wang HJ, Murphy PA. Defining food components as new nutrients. J Nutr. 1994;124(Suppl 9):1789S-1792S.

18. Santell RC, Chang YC, Nair MG, Helferich WG. Dietary genistein exerts estrogenic effects upon the uterus, mammary gland and the hypothalamic/pituitary axis in rats. $J$ Nutr. 1997;127(2):263-269.

19. Bhandari A, Crawford SE, Huang L, Reenstra WW. Effects of oral genistein in mice. Pediatr Pathol Mol Med. 2003;22(2):131-141.

20. Xu X, Wang HJ, Murphy PA, Cook L, Hendrich S. Daidzein is a more bioavailable soymilk isoflavone than is genistein in adult women. J Nutr. 1994;124(6):825-832.

21. Ae Park S, Choi MS, Cho SY, et al. Genistein and daidzein modulate hepatic glucose and lipid regulating enzyme activities in C57BL/KsJ-db/ $\mathrm{db}$ mice. Life Sci. 2006;79(12):1207-1213.

22. Ørgaard A, Jensen L. The effects of soy isoflavones on obesity. Exp Biol Med (Maywood). 2008;233(9):1066-1080.

23. Goodman-Gruen D, Kritz-Silverstein D. Usual dietary isoflavone intake is associated with cardiovascular disease risk factors in postmenopausal women. J Nutr. 2001;131(4):1202-1206.

24. Kim HK, Nelson-Dooley C, Della-Fera MA, et al. Genistein decreases food intake, body weight, and fat pad weight and causes adipose tissue apoptosis in ovariectomized female mice. J Nutr. 2006;136(2): 409-414.

25. Matori H, Umar S, Nadadur RD, et al. Genistein, a soy phytoestrogen, reverses severe pulmonary hypertension and prevents right heart failure in rats. Hypertension. 2012;60(2):425-430.

26. Samarakoon R, Higgins PJ. MEK/ERK pathway mediates cell-shapedependent plasminogen activator inhibitor type 1 gene expression upon drug-induced disruption of the microfilament and microtubule networks. J Cell Sci. 2002;115(Pt 15):3093-3103.

27. Liu XJ, Yang L, Mao YQ, et al. Effects of the tyrosine protein kinase inhibitor genistein on the proliferation, activation of cultured rat hepatic stellate cells. World J Gastroenterol. 2002;8(4):739-745. 
28. Villa P, Costantini B, Suriano R, et al. The differential effect of the phytoestrogen genistein on cardiovascular risk factors in postmenopausal women: relationship with the metabolic status. J Clin Endocrinol Metab. 2009;94(2):552-558.

29. Salih SM, Kapur A, Albayrak S, Salama SA, Magness RR. Pregnancy ameliorates the inhibitory effects of 2-methoxyestradiol on angiogenesis in primary sheep uterine endothelial cells. Reprod Sci. 2011;18(9): 858-867.

30. Sorenson RL, Brelje TC, Roth C. Effect of tyrosine kinase inhibitors on islets of Langerhans: evidence for tyrosine kinases in the regulation of insulin secretion. Endocrinology. 1994;134(4):1975-1978.

31. Veloso RV, Latorraca MQ, Arantes VC, et al. Soybean diet improves insulin secretion through activation of $\mathrm{cAMP} / \mathrm{PKA}$ pathway in rats. J Nutr Biochem. 2008;19(11):778-784.

32. Fu Z, Zhang W, Zhen W, et al. Genistein induces pancreatic beta-cell proliferation through activation of multiple signaling pathways and prevents insulin-deficient diabetes in mice. Endocrinology. 2010;151(7): 3026-3037.

33. Huppertz C, Fischer BM, Kim YB, et al. Uncoupling protein 3 (UCP3) stimulates glucose uptake in muscle cells through a phosphoinositide 3-kinase-dependent mechanism. J Biol Chem. 2001;276(16): $12520-12529$.
34. Lee MS, Kim CH, Hoang DM, et al. Genistein-derivatives from Tetracera scandens stimulate glucose-uptake in L6 myotubes. Biol Pharm Bull. 2009;32(3):504-508.

35. Ha BG, Nagaoka M, Yonezawa T, et al. Regulatory mechanism for the stimulatory action of genistein on glucose uptake in vitro and in vivo. J Nutr Biochem. 2012;23(5):501-509.

36. Massion PB, Feron O, Dessy C, Balligand JL. Nitric oxide and cardiac function: ten years after, and continuing. Circ Res. 2003;93(5) 388-398.

37. Kojda G, Kottenberg K. Regulation of basal myocardial function by NO. Cardiovasc Res. 1999;41(3):514-523.

38. Prendergast BD, Sagach VF, Shah AM. Basal release of nitric oxide augments the Frank-Starling response in the isolated heart. Circulation. 1997;96(4):1320-1329.

39. Maulik SK, Prabhakar P, Dinda AK, Seth S. Genistein prevents isoproterenol-induced cardiac hypertrophy in rats. Can J Physiol Pharmacol. 2012;90(8):1117-1125.

40. Lichtenstein AH. Soy protein, isoflavones and cardiovascular disease risk. J Nutr. 1998;128(10):1589-1592.

41. Tissier R, Waintraub X, Couvreur N, et al. Pharmacological postconditioning with the phytoestrogen genistein. J Mol Cell Cardiol. 2007;42(1):79-87.
Nutrition and Dietary Supplements

\section{Publish your work in this journal}

Nutrition and Dietary Supplements is an international, peer-reviewed, open access journal focusing on research into nutritional requirements in health and disease, impact on metabolism and the identification and optimal use of dietary strategies and supplements necessary for normal growth and development. The journal welcomes papers covering

\section{Dovepress}

original research, basic science, clinical \& epidemiological studies, reviews and evaluations, guidelines, expert opinion and commentary, case reports and extended reports. The manuscript management system is completely online and includes a very quick and fair peer-review system, which is all easy to use.

Submit your manuscript here: http://www.dovepress.com/nutrition-and-dietary-supplements-journal 